tion was to obtain some first-hand information concerning the blood changes in workers in lead, especially as regards the significance of the presence of basophile granules in the red corpuscles (the "erythrocytes ponctués" of French writers), and the conditions under which they occur.

The men examined were all adult males. Most of them were employed at the works of the Chloride Electrical Storage Co. at Clifton Junction, in various ways involving contact with lead. Three men were undoubted cases of lead-poisoning, not employed by the Chloride Company, but sent to the works to obtain bath treatment.

The conclusions arrived at were as follows :-

(I) The presence of basoohile granules in the blood of lead workers affords very strong evidence of lead absorption, but in itself is no absolute proof of lead poisoning. It would appear wrong to exclude such cases from following their ordinary work, but they should be regarded as a special class, and kept under close observation. The knowledge of the existence of such cases in a factory would certainly facilitate the work of inspection.

(2) Blood examinations are of great value in cases where the clinical symptoms are doubtful, and in cases of suspected malingering or imaginary illness. In such cases a positive finding would at all events go to show that lead absorption had occurred. A negative result is of less significance, though it has a certain value.

Dr. S. Rideal, of London, in a paper read before the Domestic Hygiene Section of the congress, discussed the use of paper utensils in the home as a substitute for glass and china or earthenware. The argument for the use of paper plates, cups and saucers, which can be destroyed after use, was based chiefly on the fact that recent scientific investigation has proved that cups taken from schools, stores, and hotels have been found infected with several pathogenic forms of bacteria (including those of diphtheria, pneumonia, and influenza), even when supposed to be clean and ready for use. At one of the largest hospitals there is a regulation that all crockery, cutlery, glass, etc., should be rinsed in a disinfectant before being used again. In these days of typhoid and diphtheria "carriers," the public are entitled to expect the adoption of similar precautions in places of refreshment; but this, of course, involves expense and labour.

Samples of the following articles, made in paper, were exhibited at the close of the address, which aroused much interest and a keen discussion :Cups: automatic dispenser; collapsing. Plates, table-covers; handkerchiefs; towels (various); blind; spitting-cup; formaldehyde generator (home-made). Bags: coke bag; moth bag; bags for cookery.

\section{PALISSY AS A PIONEER OF SCIENTIFIC METHOD.}

GVERYONE is familiar with the dramatic story of Bernard Palissy, the potter, and how he fired a kiln with his household furniture in order to produce sufficient heat to melt his glazes, but his scientific work is rarely mentioned. A paper on "Palissy, Bacon, and the Revival of Natural Science," by Sir T. Clifford Allbutt, published in the Proceedings of the British Academy (vol. vi.) is therefore a welcome contribution to the history of science.

Palissy shares with Galileo and Gilbert the credit of being a pioneer of modern scientific method. Born in 1519, in Périgord, he was apprenticed to the art of glass painting, and in ${ }_{539}$ saw the cup of glazed faience which inspired him to produce a similar glaze upon ware. After he had succeeded, he found his way to Paris, where he wrote books on many scientific subjects; and during the years $1575^{-84}$ he exercised great influence upon society in the city. He lectured on agriculture, chemistry, mineralogy, and geology, and illustrated his lectures with demonstrations of natural objects from his museum. "Into the faces of the learned of his time he thrust his facts; he urged the might of the verified fact, the tests of practical experience, the demonstration of the senses; and these in a keen and original way." Among the physicians who attended his lectures was no less a person than Ambrose Paré.

By observation and experiment Palissy combated the prevailing notion that springs originated in the percolation of sea-water into the earth; and he showed that they were formed at the junction of permeable and impermeable strata. He collected fossils widely and understood their nature; and both Buffon and Réaumur bore testimony to the correctness of his judgments upon this and other geological subjects. At the age of eighty Palissy was thrown into the Bastille as a dangerous heretic, and he died there after enduring about a year's imprisonment.

Sir Clifford Allbutt suggests that Francis Bacon, who went to Paris in ${ }^{5} 576$, and resided there for three years, must have been influenced by Palissy's Museum or lectures, though no mention of them is found in any existing work "What is certain is that Palissy was then teaching practically the methods which a few years afterwards Bacon propounded at length; and not only so, but was teaching them, if with a far inferior literary capacity, yet with a sounder grasp of their methods."

Bacon constructed an imposing philosophical system of rules by which natural facts and phenomena were to be studied, but it was Palissy, Gilbert, and Galileo who were the real founders of the experimental method of inquiry upon which the superstructure of modern science has been built.

\section{EXPLOSIVES. ${ }^{1}$}

$A \mathrm{~N}$ explosive is a body which, under the influence of heat or shock, or both, is, speaking popularly, instantaneously resolved entirely, or almost so, into gases.

Practical explosives consist either of bodies such as nitroglycerine and nitrocellulose, which are explosive in themselves, or mixtures of ingredients which separately are, or may be, non-explosive, but when intimately mixed are capable of being exploded.

Explosives are exploded either by simple ignition, as in the case of black gunpowder, or by means of a detonator containing mercury fulminate.

The molecules of an expiosive may be regarded as in a state of unstable chemical equilibrium. A stable state of equilibrium is brought about by the sudden decomposition of the original compounds with the evolution of heat. An explosion is thus an extremely rapid decomposition, accompanied by the production of a large volume of gas and the development of much heat.

There are two well-defined modes of explosion which can be described as combustion and detonation. In the former case, the explosive is simply ignited and combustion takes place by transference of heat from layer to layer of the explosive. The rapidity with which the combustion proceeds depends not only on the physical form of the explosive, but also on the pressure under which the decomposition takes place. When in the form of fine grains, combustion pro-

1 From a course of lectures delivered before the Institute of Chemistry, at King's Coll

NO. 2333, VOL. 93] 
ceeds much more quickly than when the grains are large, and the powder maker takes advantage of this fact in preparing powder for rifles and the various sized large guns.

Detonation, on the other hand, has to be started by a sufficiently strong impulse, such as the explosion of a charge of mercury fulminate; it proceeds much more rapidly and is due to the formation of an explosion oxidation, the products are carbon dioxide, carbon monoxide, hydrogen, water, and nitrogen, but the relative proportions vary with the pressure developed. When such an explosive is fired in a closed vessel under different densities of charge, that is, different quantities of explosive in the same volume, the volume and composition of the gas varies with the pressure developed by the explosion. The carbon dioxide and

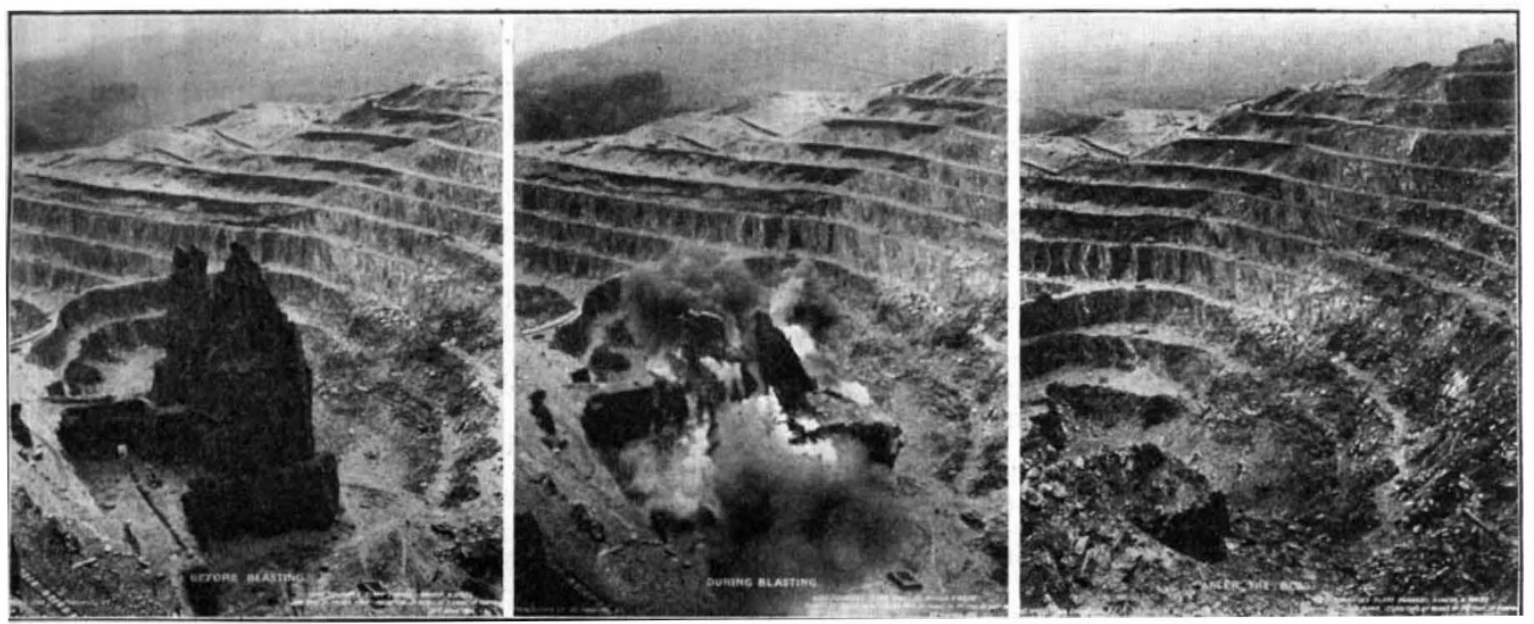

Ftg. I,-Blast at Lord Penrhyn's slate quarries.

wave that has a velocity of thousands of metres a second.

Black gunpowder and allied explosives, as well as the smokeless powders, belong to the first or combustion class, and they are commonly designated "low" explosives.

"High" explosives indicate those, such as dynamites and nitrate of ammonia explosives, which detonate

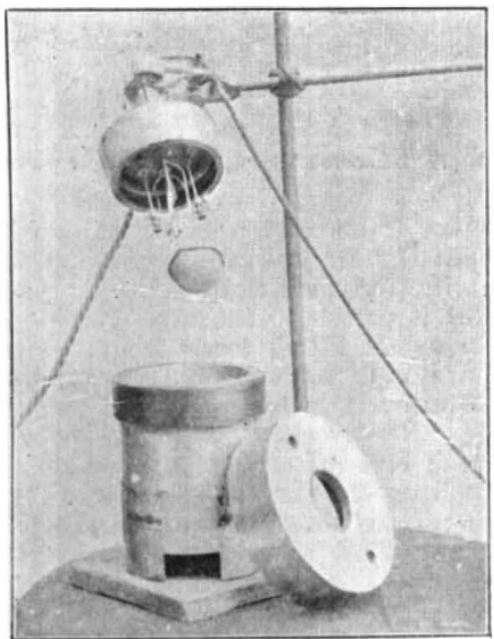

F1G. 2. - Berthelot calori-metric bomb.

and have a greater shattering action than the former.

The volume and composition of the gas produced, both in regard to the power of the explosive, and, in the case of mining explosives, the health of the miner, are of great importance. These gases are largely determined by the original composition of the explosive.

When there is insufficient oxygen for complete hydrogen increase and the carbon monoxide and water diminish as the pressure increases; also, at high pressures, considerable amounts of methane are formed. In the foregoing, it has been assumed that complete explosive decomposition has taken place.

When a high explosive burns, instead of explodes, the chemical changes are not only very much slower and the disruptive effect practically nil, but the char-

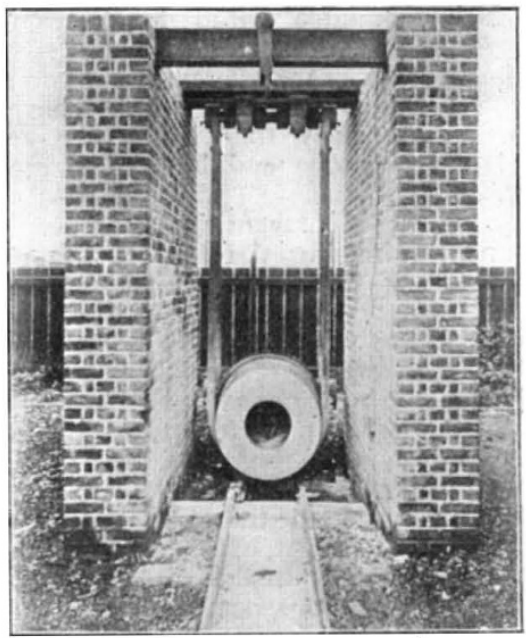

FIG. 3.-Ballistic pendulum, Home Office testirg station.

acter of the gases is entirely changed, large volumes of poisonous nitrous fumes along with other gases being produced.

The temperature developed by an explosive is of importance, because the higher the temperature the greater the erosion of the guns.

Nearly all blasting explosives, except black powder, are fired by means of a detonator. Fulminate of 
mercury is the most widely employed constituent of the detonator charge; sometimes it is used alone, but more usually with an admixture of 20 per cent. of potassium chlorate.

Trinitrotoluene, picric acid, and tetranitromethylaniline, each with a small quantity of fulminate as primer, have also been used for charging detonators.

More recently lead azide prepared from the sodium salt of hydrazoic acid $\mathrm{N}_{3} \mathrm{H}$, by means of a lead salt, has also been used, as it has a greater power of initiating detonation, so that less azide is required to detonate an organic explosive than would be required of fulminate. Its manufacture, how'ever, is more delicate than fulminate, and the formation of large crystals must be avoided, as they have the unpleasant property of sometimes exploding spontaneously.

Another new explosive body which appears likely to play an important part as a charge for detonators is tetranitroaniline, manufactured by nitrating metanitroaniline. It combines an exceptional explosive power with aromatic stability and has a high density.

It can be easily detonated, even when highly com pressed, and has such a high percentage of oxygen that it can be detonated without residue or smoke.

In blasting operations, gunpowder and detonators are either fired by a time fuse or electrically. The time fuse consists of a thin but continuous core of black powder covered by a case of twine and tape and varnish. It is made to burn at a known uniform rate, generally $2 \mathrm{ft}$. a minute, in order that a sufficient length can be used to allow the shot-firer, after lighting the fuse, to reach shelter before the explosion takes prace.

The instantaneous fuse, which burns at the rate of roo-300 ft. a second. affords a mean of firing many charges simultaneously.

Occasionally it happens that a coil is defective, generally through discontinuity in the powder core. C. Napier "Hake, late Chief Inspector of Explosives for Victoria, ingeniously employed X-ray photography to examine suspected coils, and, in this way, was able to recognise those which were defective.

One of the most interesting recent productions is the "detonating fuse," a soft metal tube filled with trinitrotoluene which detonates with greater velocity than most explosives. When placed alongside the cartridges in a deep borehole, it is considered to give an enhanced blasting effect by causing the whole charge to go off more simultaneously than when the column of explosive is fired at one end by a detonator in the usual way.

With the object of preventing accidents so far as possible, and minimising the loss of life should an explosion occur, a number of rules and regulations have been drawn up by the Explosives Department of the Home Office which have to be followed in the construction and working of explosive factories.

The object of the restrictions is to allow only limited quantities of explosive material and a limited number of workpeople in one building at a time, and, further, to place the different buildings at such distances from each other, or surround them by protecting earth mounds, that in the event of an explosion the effect is localised as much as possible and the explosives in the adjacent buildings are not "set-off."

The manufacture of guncotton and the other forms of nitrocellulose is carried out in the first stages in the non-danger part of the factory.

The most interesting development of the nitration process is the method devised by J. and W. Thomson, of the Royal Gunpowder Factory, Waltham Abbey.

The composition of the acid mixture is of the greatest importance and largely determines the character of the product. The ratio between the nitric and sulphuric acids and the water must be accurately adjusted.

NO. 2333, VOL. 93]
It must also be remembered that the cotton is by no means a definite chemical body, and its physical state plays an important part. Samples of different cottons, under the same conditions in a bath of the same composition, while yielding nitrocelluloses containing practically the same percentage of nitrogen, may vary in solubility in ether-alcohol from 25 per cent. to 70 per cent.

Turning now to the production of nitroglycerine, this manufacture is much simpler than that of nitrocellulose; at the same time, it is much more dangerous.

The plant which is at present most employed is known as the nitrator-separator. It was developed at Waltham Abbey by Sir Frederic Nathan and IV. Rintoul, and is a great advance on the former methods.

The nitrator-separator is a cylindrical leaden vessel with a coned top; inside are placed leaden coils, through which cooling water circulates, and pipes, through which compressed air is blown to mix the contents. The glycerine is introduced in the form of a fine spray under the acid by means of a special injector, worked also by compressed air.

When everything goes right, the nitration of the

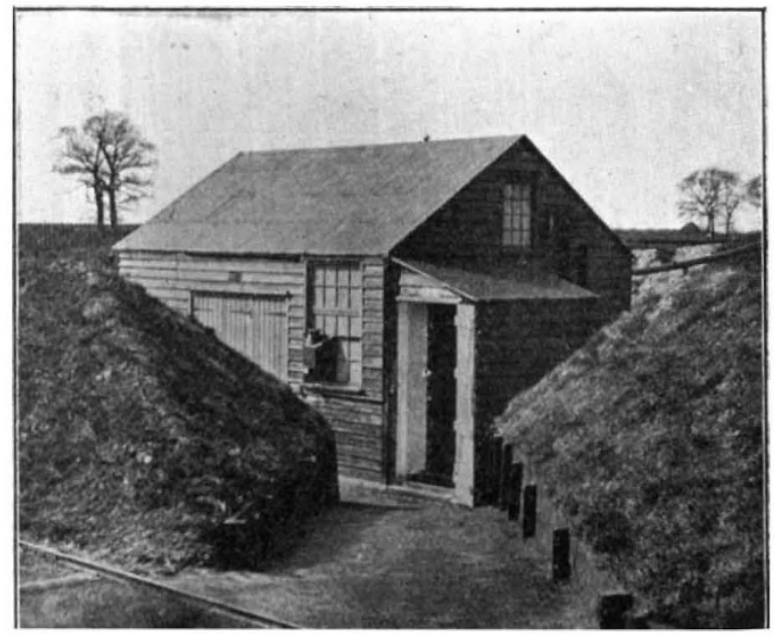

FIG. 4.- "Mounded" house, Cotton Powder works.

charge is usually completed in about one hour; the agitation with the air is discontinued and the separation of the nitroglycerine from the acids takes placebeing lighter it comes to the top. A pipe, in which a glass window is fitted, leads from the top of the nitrator-separator to a pre-washing tank; by allowing waste acid from a previous operation to enter at the bottom, the nitroglycerine is forced over into the washing tank; and the flow of acid is stopped whenever all the nitroglycerine has passed into the washing tank, which can be observed through the window.

With the object of preventing explosions of gas or coal-dust in mines, our Government, in common with many others, has instituted a test which explosives have to pass before they are put on the "permitted" list, and are available for use in fiery or dusty mines. This test has varied in the different countries, and a change has been introduced recently, since the transference of the testing station from Woolwich to Rotherham. Much difference of opinion still exists as to the best means of carrying out such a test.

One of the chief factors in determining the ignition is the temperature developed by the gases of explosion. Owing to lack of data, the temperature cannot be calculated with sufficient accuracy, and other condi- 
tions obtain which make a practical test more helpful. Nevertheless, the temperature is of great importance and many means are employed of lowering it, such as adding salts which absorb heat on volatilisation.

The rapidity of detonation, the length of the flame, and the heat evolved, all influence the readiness with which explosives ignite gas or coal-dust; but in this connection knowledge and progress have been chiefly promoted by direct experiment at the various testing stations here and abroad.

The filling material for shells has been the subject of much experiment and trial by the different countries. Picric acid, under the various names of melinite, lyddite, shimose powder, etc., has been extensively tried and found wanting. Ammonal, containing ammonium nitrate, with a large percentage of trinitrotoluol and finely divided aluminium, is a very safe and powerful explosive, and has been adopted as the charge for shells by the Austrian Government. It has the disadvantage of containing the hygroscopic ammonium nitrate as an ingredient, and must consequently be specially protected against moisture. At present, trinitrotoluol is the body which has commended itselt to most of the Governments as the best bursting charge for shells, torpedoes, and general military blasting work, and has just been adopted by our own Government.

Experience in America, South Africa, and Australia has shown that the fruit-grower has a real friend in explosives, and it seems to me that, in this country also, we must wake up to this beneficent aspect of explosives and the means they offer of attaining results otherwise impossible.

In the case of tree planting, it is not the mere comparison of the cost of the excavation of the hole in which to place the tree which has to be considered. When an explosive is employed, the soil is shaken up and fissured for a comparatively wide area beyond the hole actually required for the tree. When, as often happens, there is a hard and impervious subsoil beyond reach of the spade, this is also opened and fissured, and experience has shown that trees planted in ground prepared by explosives make a much more vigorous and rapid growth than when planted in the ordinary way. Some trees have begun bearing after four years, while others similarly situated but spade planted did not yieid fruit until six years.

In the case of existing orchards little can be done in the ordinary way to aerate or render the soil more pervious to the roots and moisture, but a small cartridge inserted at some depth below the tree, or a larger one exploded at a depth of $3 \mathrm{ft}$. or so below the surface and midway between trees planted about I5 ft. apart, has a most beneficial effect in loosening the soil without injuring the trees. The roots have less resistance to overcome, the soil is aerated, the moisture retaining properties improved, and a new lease of life is thus given to an old orchard; the trees become more vigorous and productive, and indeed are rejuvenated.

\section{UNIVERSITY AND EDUCATIONAL INTELLIGENCE.}

LEEDS.-The following appointments have been made :-Mr. Howard Priestman to be lecturer in textile industries; Dr. A. M. Pryce to be demonstrator in bacteriology; Dr. H. E. Woodman to be research assistant in animal nutrition; Mr. H. A. Wyllie to be additional assistant lecturer and demonstrator in agriculture.

The second annual Yorkshire Summer School of
Geography will be held at Whitby on August 3-22. The work of organisation has again been undertaken by the University of Leeds, and the director of the school will be Prof. Kendall. The special subject this year will be the British Isles, treated in a general course, dealing with land forms and structure, meteorology and economic geography. There will be alternative courses at the choice of each student on (1) agriculture, rocks and soils, and (2) oceanography, rivers and river development, and the evolution of transport. As in last year's course, special attention will be paid to practical and field work.

London.- The council of Bedford College has made the following appointments:-Assistant-lecturer in mathematics, Mr. C. Clemmow; demonstrators in physiology, Miss G. Hartwell and Miss N. Tweedy; demonstrators in chemistry, Miss E. Field and Miss B. M. Paterson; demonstrator in geology, Miss I. Lowe.

Dr. F. R. Miller, of the department of physiology; McGill University, Montreal, has been appointed professor of physiology in the Western University, London, Canada.

THE distribution of prizes at the Horticultural College, Swanley, Kent, will be held on July 23. The prizes will be presented by Lady Reid, and Sir George Reid, G.C.M.G., High Commissioner for Australia, will give an address. The chair will be taken at 4 p.m. by Sir John Cockburn, K.C.M.G.

THE governors of the Imperial College of Science and Technology have appointed Dr. A. N. Whitehead F.R.S., to the newly constituted chair of applied mathematics, and Dr. C. G. Cullis to the professorship of economic mineralogy. These changes form part of the general scheme of development of the Imperial College "for the provision of the fullest equipment for the most advanced training and research in various branches of science, especially in its application to industry."

THREE issues of the Undergraduate, the University of London magazine, published by the Students' Representative Council, have been received. The first issue announced in December last that four numbers of the magazine would be published during the current session, and gave the last day for receiving contributions for the next issue as "Igth January, I9I4." Yet the second number bears the date May, I9I4, and it says nothing of the number of issues during the session. The third issue is dated July, I9I4. Sir Henry Miers writes in the December issue :- "A magazine which will represent the University as a whole, and will give to all its members a medium of free expression upon the numerous and increasing matters of University interest will ... satisfy a very real need." We trust that the magazine will meet with the success to which the variety and interest of its contents entitle it.

\section{SOCIETIES AND ACADEMIES. LONDON.}

Royal Society, June 25.--Sir William Crookes, president, in the chair--Sir W. Crookes: The spectrum of elementary silicon. The author has tried in vain for years to get pieces of fused silicon in an approximate degree of purity. Lately the Carborundum Co. at Niagara Falls sent him three samples giving an analysis of $99^{\circ} 5^{6}, 99^{\circ} 86$, and $99^{\circ} 9^{8}$ per cent. 